\title{
Mammographic Density and Matrix Metalloproteinases in Breast Tissue
}

\author{
Jana S. Steude • Gertraud Maskarinec • Eva Erber • \\ Martijn Verheus • Brenda Y. Hernandez • \\ Jeffrey Killeen • J. Mark Cline
}

Received: 10 August 2009/Accepted: 10 November 2009/Published online: 10 December 2009

(C) The Author(s) 2009. This article is published with open access at Springerlink.com

\begin{abstract}
Mammographic density is a strong risk factor for breast cancer, yet the underlying histopathologic correlates are not clear. Matrix metalloproteinases (MMPs) and their inhibitors (TIMPs) play important roles in multiple stages of tumorigenesis. This study examined the association between mammographic density and expression of MMPs $1,3,9$, and 12 and TIMP3 in benign and malignant breast tissue of 277 women with mainly Caucasian and Japanese ancestry. Tissue microarrays with up to 4 benign and 4 malignant cores per woman were stained immunohistochemically and evaluated. Digitized prediagnostic mammograms were assessed for densities using a computer-assisted method. General linear models adjusted for known confounders were applied to estimate mean densities by staining category. Strong expression of all MMPs was about twice as frequent in malignant as in benign tissue, while TIMP3 expression in stromal tissue was higher in benign than malignant cores. For MMP3 and 9, less than $10 \%$ of cores stained positive; thus, they were not further analyzed. None of the markers showed a statistically significant association with breast density in the entire
\end{abstract}

J. S. Steude $\cdot$ G. Maskarinec $(\bowtie) \cdot$ E. Erber $\cdot$ M. Verheus •

B. Y. Hernandez $\cdot$ J. Killeen

Cancer Research Center of Hawaii,

1236 Lauhala Street,

Honolulu, HI 96813, USA

e-mail: gertraud@crch.hawaii.edu

J. M. Cline

Department of Pathology, Wake Forest

University School of Medicine,

Winston-Salem, NC 27157-1070, USA

J. Killeen

Kapiolani Medical Center for Women and Children,

Honolulu, HI, USA study population and ethnic-specific results were conflicting and difficult to explain. Although not statistically significant, mean density was consistently lower with more extensive TIMP3 expression in stromal and epithelial tissue. These findings indicate that the higher breast cancer risk in women with dense breasts may be influenced by lower TIMP3 expression. However, future investigations into activities and ratios of additional proteases and their inhibitors as well as other pathways, such as inflammation, are needed.

Keywords Breast cancer - Immunohistochemistry · Stroma . Mammographic density $\cdot$ Ethnicity

\section{Introduction}

Breast density, one of the strongest breast cancer risk factors, refers to the radiographic appearance of the female breast $[1,2]$. Fat, which is radiolucent, appears dark on a mammogram. Epithelial and stromal tissues, on the other hand, appear white or radiodense and are collectively referred to as mammographic density. As stroma is present in much larger quantities than epithelium [3], it accounts for most of the radiological density [4, 5]. Despite several reports on breast density and proliferative lesions of breast tissue $[6,7]$, a full understanding of the cellular basis of breast density and a biological mechanism for the positive association with breast cancer risk, however, has yet to be developed.

Growing evidence supports the notions that altered regulation of extracellular matrix (ECM) contributes to neoplastic progression and that disruptions in the ECM may precede epithelial changes [8]. Matrix metalloproteinases (MMPs), zinc-dependent endopeptidases involved in 
remodeling of ECM, contribute to all steps of tumor progression, including promotion, angiogenesis, and metastatic lesions $[9,10]$. A disruption of the balance between MMPs and their tissue inhibitors has been implicated in cancer progression [11]. The importance of stromal composition in relation to breast density was shown by a stronger association of mammographic density with stromal than epithelial composition and higher collagen density and stronger proteoglycan expression in mammographically dense tissue [3]. A similar study found greater amounts of collagen and higher TIMP3 expression in dense breasts [12].

Our objective was to investigate the association of breast density with expression of MMPs 1, 3, 9, and 12 and a tissue inhibitor of MMPs (TIMP3) in breast tissue of women with different ethnic backgrounds who participated in a case-control study of breast density [13]. We propose that MMPs and their inhibitors play a crucial role in breast density formation through degradation of ECM and activation of growth factors which may lead to the associated increased breast cancer risk. We hypothesize that changes in MMP expression in tumor tissue reflect activity in benign tissue in the same subjects.

\section{Materials and Methods}

Study Population The current study is based on subjects of the Hawaii component of the Multiethnic Cohort (MEC) [14] who took part in a nested case-control (NCC) study of mammographic densities and breast cancer risk [13]. The MEC study investigates the association between diet and cancer in 215,251 adult men and women of different ethnic backgrounds [14]. Participants entered the MEC study in 1993-96 by completing a mail questionnaire asking for dietary, demographic, anthropometric, and reproductive information [14]. Additional information on hormone replacement therapy (HRT), menopausal status, breast surgery, and mammograms was obtained when subjects enrolled in the NCC study [13]. Data from the Hawaii component of the MEC study is linked annually to the Hawaii Department of Health and the statewide Hawaii Tumor Registry (HTR) to identify deaths and cancer cases. The study was approved by the Institutional Review Boards of the University of Hawaii and Wake Forest University; all subjects provided informed consent in writing.

We mailed invitations for the pathology study to 430 women out of the 607 cases in the NCC study $[15,16] ; 177$ women were not contacted because the respective hospitals were not participating or because the subjects were deceased at the time of recruitment. Tissue was available for 279 of 430 women after exclusions for a variety of reasons (refusals, too ill to participate, did not sign the consent form, not linked to HTR, tissue blocks not available from hospital, or not sufficient tissue in tissue blocks) and after inclusion of 12 deceased women with tumor blocks in the HTR. Since tissue cores for two women could not be evaluated, the final number of included subjects was 277 (Table 1).

Mammographic Density Assessment Mammographic films of study participants from clinics throughout the State of Hawaii were retrieved and digitized using a Kodak LS 85 Film Digitizer (Kodak, Rochester, NY) with a pixel size of $260 \mu \mathrm{m}$ [13]. For the pathology study, results of craniocaudal views closest to, but before, the date of diagnosis were selected. Using the Cumulus software developed at the University of Toronto, Canada [17], the scanned images for both breasts were assessed for densities by one reader (GM) who was blinded to case status and time sequence of mammograms. Films were randomized by subjects and films within subjects were viewed one after the other without knowledge of the temporal order [18]. After the reader determined a threshold for the edge of the breast and for the dense tissue, the computer calculated the ratio of the total number of pixels that constituted the breast area and the dense area. The intraclass correlation coefficients derived from duplicate readings were 0.96 for the size of the dense area and 0.97 for percent density [13]. Because of the high correlation between readings from the right and the left breast, means were used for the analysis.

Breast Tissue Tissue blocks for this study were retrieved through the tissue repository of the HTR $[15,16]$. Tissue microarrays (TMA) were prepared according to standard procedures $[19,20]$. In brief, a surgical pathologist (JK) identified appropriate tissue blocks from a given patient and prepared a single hematoxylin and eosin (H\&E) slide on which representative areas of malignant and benign tissue were marked. The H\&E slide was aligned with the corresponding "donor" tissue block and a $0.6 \mathrm{~mm}$ cylindrical tissue specimen was taken from the selected area and transferred to a "recipient" paraffin block using a tissuearraying instrument (Beecher Instruments, Sun Prairie, WI). When available, 4 malignant and 4 benign cores per patient were placed in one of 6 paraffin blocks. Out of the 2,232 possible (4 malignant and 4 benign samples for 279 women) specimens, 459 cores $(20.6 \%)$ could not be placed due to insufficient tissue in the respective block $(29.2 \%$ malignant and $70.8 \%$ benign samples). Overall, 1,773 (79.4\%) tissue samples were successfully placed in the TMA blocks. Following TMA construction, $5 \mu \mathrm{m}$ sections of TMA blocks were sent to Wake Forest University for immunohistochemical staining with the following markers: MMP1 (1906-1), MMP3 (1908-1), MMP9 (1939-1), MMP12 (1906-1; all Epitomics, Inc., Burlingame, CA), 
Table 1 Characteristics of women in the pathology study
${ }^{a}$ Includes Native Hawaiian and other ethnicities, which are not shown separately

${ }^{\mathrm{b}}$ Mean values are given

\begin{tabular}{|c|c|c|c|}
\hline Variable & All women ${ }^{\mathrm{a}}$ & Japanese & Caucasian \\
\hline Sample size & 277 & 119 & 97 \\
\hline Age at mammogram ${ }^{\mathrm{b}}$ & $60.2 \pm 8.7$ & $60.6 \pm 8.5$ & $61.4 \pm 8.6$ \\
\hline Body mass index $\left(\mathrm{kg} / \mathrm{m}^{2}\right)^{\mathrm{b}}$ & $24.8 \pm 4.4$ & $24.3 \pm 3.3$ & $24.4 \pm 4.7$ \\
\hline Family history of breast cancer & $42(15 \%)$ & $18(15 \%)$ & $11(11 \%)$ \\
\hline \multicolumn{4}{|l|}{ Age at menarche } \\
\hline$<13$ years & $154(56 \%)$ & $73(61 \%)$ & $49(51 \%)$ \\
\hline $13-14$ years & $97(35 \%)$ & $40(34 \%)$ & $36(37 \%)$ \\
\hline$>14$ years & $26(9 \%)$ & $6(5 \%)$ & $12(12 \%)$ \\
\hline \multicolumn{4}{|l|}{ Number of children } \\
\hline $0-1$ & $84(30 \%)$ & $32(27 \%)$ & $33(34 \%)$ \\
\hline $2-3$ & $139(50 \%)$ & $63(53 \%)$ & $49(51 \%)$ \\
\hline$>3$ & $54(20 \%)$ & $24(20 \%)$ & $15(16 \%)$ \\
\hline \multicolumn{4}{|l|}{ Age at first live birth } \\
\hline$<21$ years & $40(14 \%)$ & $9(8 \%)$ & $15(16 \%)$ \\
\hline $21-30$ years & $166(60 \%)$ & $81(68 \%)$ & $56(58 \%)$ \\
\hline$>30$ years & $22(8 \%)$ & $11(9 \%)$ & $7(7 \%)$ \\
\hline N/A & $49(18 \%)$ & $18(15 \%)$ & $19(20 \%)$ \\
\hline \multicolumn{4}{|l|}{ Menopausal status } \\
\hline Pre & $75(27 \%)$ & $36(30 \%)$ & $15(16 \%)$ \\
\hline Post & $202(73 \%)$ & $83(70 \%)$ & $82(85 \%)$ \\
\hline \multicolumn{4}{|l|}{ Hormone use at mammogram } \\
\hline No use & $125(45 \%)$ & $50(42 \%)$ & $42(43 \%)$ \\
\hline Estrogen only & $83(30 \%)$ & $40(34 \%)$ & $30(31 \%)$ \\
\hline Estrogen plus progesterone & $69(24 \%)$ & $29(24 \%)$ & $25(26 \%)$ \\
\hline Breast density (\%) & $37.7 \pm 23.5$ & $39.7 \pm 23.3$ & $35.6 \pm 24.0$ \\
\hline \multicolumn{4}{|l|}{ Tumor stage } \\
\hline In situ & $61(22 \%)$ & $26(22 \%)$ & $24(25 \%)$ \\
\hline Localized & $169(61 \%)$ & $74(62 \%)$ & $54(56 \%)$ \\
\hline Regional & $36(13 \%)$ & $16(14 \%)$ & $12(12 \%)$ \\
\hline Unknown & $11(4 \%)$ & $3(3 \%)$ & $7(7 \%)$ \\
\hline
\end{tabular}

and TIMP3 (CA 0577; Cell Applications, Inc., San Diego, $\mathrm{CA})$. The basic staining procedure used an avidinbiotin-alkaline phosphatase method, modified for antigen retrieval from paraffin-embedded tissue using the procedure of Shi et al. [21]. A trained pathologist (JMC) reviewed all stained specimens to confirm tissue type and malignancy status. The stained slides were scanned by Aperio Scanning Services (Aperio Technology, Inc., Vista, CA) and the digital images were evaluated by one of the authors (JSS). Because the proportion of stained specimens was very small, stromal staining was dichotomized into no vs. any stain, while epithelial staining was classified as no, weak, or strong according to intensity (Fig. 1). We assigned the values for the highest level of staining for stromal and epithelial to each subject.

During staining, about $4-8 \%$ of cores fell off with similar proportions across all markers. On average, 3.5 malignant and 2.9 benign cores per women were available for evaluation. After excluding core sections with equivocal features, i.e., incomplete core, fatty tissue only, or bad staining quality, 259 women had at least one benign stromal and 274 women had at least one malignant stromal measurement. Yet, measurements for benign epithelial tissue were only available for 169 women after excluding cores with connective tissue only.

Statistical Analysis Data management and statistical analysis were performed using the SAS statistical software, version 9.1 (SAS Institute Inc., Cary, NC). General linear models were applied to determine the relation between markers and mammographic densities, while adjusting for covariates that are known to be associated with breast density: age at mammogram, body mass index (BMI) as continuous variable, ethnicity (Hawaiian, Japanese, Caucasian, Other), parity $(0-1,2-3,>3)$, age at first live birth (nulliparous, $<21,21-30,>30$ years), age at menarche $(<13,13-14,>14$ years), menopausal status at mammogram, HRT use at mammogram (no use, estrogen only, 


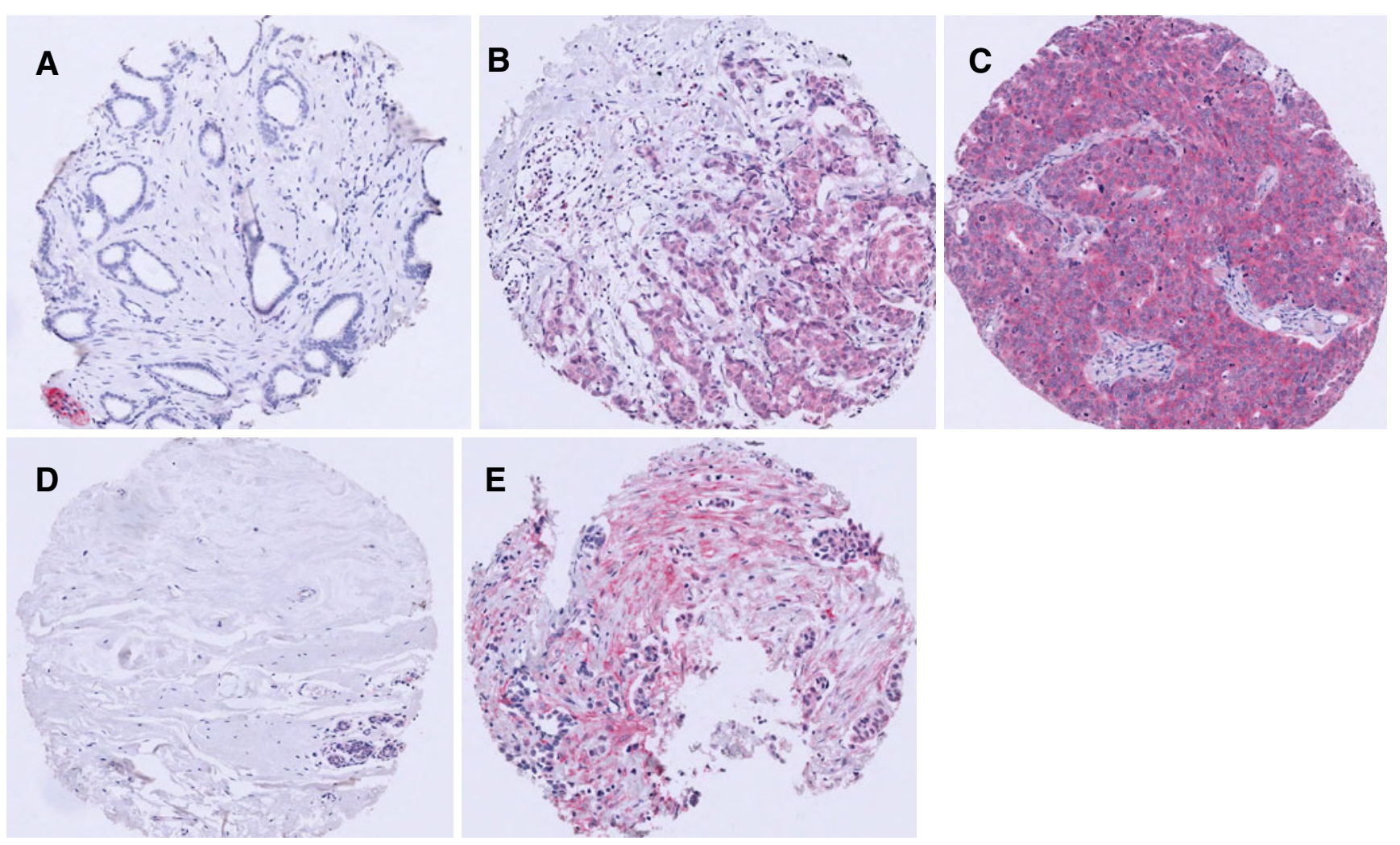

Representative immunohistochemical staining on breast tissue microarray

A-C: Epithelial staining; A: no stain, B: weak stain, C: strong stain

D-E: Stromal staining; D: no stain, E: any stain

Fig. 1 Examples of stromal and epithelial staining in tissue microarray. Representative immunohistochemical staining on breast tissue microarray. $\mathbf{a}-\mathbf{c}$ Epithelial staining; a no stain, $\mathbf{b}$ weak stain, $\mathbf{c}$ strong stain. $\mathbf{d}-\mathbf{e}$ Stromal staining; $\mathbf{d}$ no stain, e any stain

estrogen/progesterone), family history of breast cancer in a first degree relative (yes, no), and tumor stage (in situ, localized, regional, unknown). All analyses were conducted separately for malignant and benign tissue and stratified by ethnicity.

\section{Results}

This analysis included 277 breast cancer cases with primarily Caucasian (35\%) and Japanese (43\%) ancestry (Table 1). The mean age at mammogram was $60.2 \pm 8.7$ years. More than two-thirds of the participants were postmenopausal. Nearly all women in our study had early-stage disease consisting of carcinoma in situ $(22 \%)$ or localized invasive carcinoma $(61 \%)$. The mean percent breast density in the study population was $37.7 \pm 23.5 \%$. As expected, density was inversely associated with age $(p=0.001)$, menopausal status $(p=0.001)$, BMI $(p<0.0001)$, and parity $(p=0.002)$, whereas a later age at first live birth $(p=0.007)$ and HRT use $(p=0.002)$ were related to higher density.
Positive staining of MMP3 and MMP9 was observed in less than $5 \%$ of stromal and less than $20 \%$ of epithelial specimens (Table 2). Therefore, we did not analyze their relation to breast density any further. In both stromal and epithelial tissue, MMP1 and MMP12 expression was higher in malignant than in benign tissue. In stromal tissue, the proportion of positive stained cells was $28 \%$ (malignant) and $20 \%$ (benign) for MMP1 $(p<0.0001)$ and $38 \%$ (malignant) and 10\% (benign) for MMP12 $(p=0.0004)$. In epithelial tissue, the percentages of strongly positive stained cells were $52 \%$ (malignant) and 36\% (benign) for MMP1 $(p<0.0001)$ and $75 \%$ (malignant) and $44 \%$ (benign) for MMP12 $(p=0.001)$. In epithelium, expression of TIMP3 was higher in malignant ( $16 \%$ strongly positive) than benign $(8 \%)$ tissue $(p=0.0001)$, whereas stromal tissue expression of TIMP3 was higher in benign $(33 \%)$ than malignant $(19 \%)$ samples $(p<0.0001)$. We observed no significant difference in staining between Japanese and Caucasians except for MMP12 in malignant tissue; the proportion stained was higher for Japanese than Caucasian women both in stromal $(p=0.056)$ and epithelial tissue $(p=0.03)$. Only for MMP1 in stromal tissue was HRT use 
Table 2 Proportion of subjects with positive stains for MMPs and TIMP3 by ethnicity

\begin{tabular}{|c|c|c|c|c|c|c|c|c|c|c|}
\hline \multicolumn{2}{|c|}{ Tissue type/marker } & \multicolumn{3}{|c|}{ All women } & \multicolumn{3}{|c|}{ Japanese } & \multicolumn{3}{|c|}{ Caucasian } \\
\hline & & \multirow[t]{2}{*}{$\mathrm{N}^{\mathrm{a}}$} & \multicolumn{2}{|l|}{ Any ${ }^{b}$} & \multirow[t]{2}{*}{$\mathrm{N}$} & \multicolumn{2}{|l|}{ Any } & \multirow[t]{2}{*}{$\mathrm{N}$} & \multicolumn{2}{|l|}{ Any } \\
\hline \multicolumn{8}{|c|}{ Stromal tissue } & & & \\
\hline \multirow[t]{2}{*}{ MMP1 } & benign & 237 & 20.3 & & 104 & 21.2 & & 82 & 18.3 & \\
\hline & malignant & 267 & 28.1 & & 114 & 27.2 & & 93 & 25.8 & \\
\hline \multirow[t]{2}{*}{ MMP3 } & benign & 242 & 0.0 & & 109 & 0.0 & & 80 & 0.0 & \\
\hline & malignant & 269 & 0.0 & & 116 & 0.0 & & 93 & 0.0 & \\
\hline \multirow[t]{2}{*}{ MMP9 } & benign & 244 & 0.8 & & 110 & 0.0 & & 82 & 0.0 & \\
\hline & malignant & 264 & 4.9 & & 116 & 4.3 & & 90 & 4.4 & \\
\hline \multirow[t]{2}{*}{ MMP12 } & benign & 220 & 10.5 & & 93 & 9.7 & & 76 & 13.2 & \\
\hline & malignant & 264 & 37.5 & & 112 & 41.1 & & 92 & 28.3 & \\
\hline \multirow[t]{3}{*}{ TIMP3 } & benign & 236 & 33.1 & & 102 & 29.4 & & 82 & 35.4 & \\
\hline & malignant & 269 & 19.0 & & 117 & 19.7 & & 93 & 21.5 & \\
\hline & & $\mathrm{N}$ & Weak & Strong & $\mathrm{N}$ & Weak & Strong & $\mathrm{N}$ & Weak & Strong \\
\hline \multicolumn{11}{|c|}{ Epithelial tissue } \\
\hline \multirow[t]{2}{*}{ MMP1 } & benign & 153 & 47.1 & 35.6 & 73 & 50.7 & 27.4 & 46 & 47.8 & 40.0 \\
\hline & malignant & 249 & 35.7 & 52.2 & 110 & 35.5 & 48.2 & 82 & 37.8 & 52.4 \\
\hline \multirow[t]{2}{*}{ MMP3 } & benign & 167 & 1.8 & 0.6 & 78 & 0.0 & & 51 & 3.9 & 0.0 \\
\hline & malignant & 253 & 5.5 & 2.4 & 110 & 6.4 & 2.7 & 85 & 3.5 & 2.4 \\
\hline \multirow[t]{2}{*}{ MMP9 } & benign & 169 & 3.6 & 0.6 & 75 & 2.7 & 0.0 & 51 & 3.9 & 0.0 \\
\hline & malignant & 249 & 9.6 & 8.4 & 111 & 9.0 & 10.8 & 82 & 7.3 & 4.9 \\
\hline \multirow[t]{2}{*}{ MMP12 } & benign & 158 & 38.6 & 43.7 & 73 & 41.1 & 35.6 & 47 & 36.2 & 51.1 \\
\hline & malignant & 256 & 19.1 & 75.0 & 111 & 18.0 & 78.4 & 86 & 24.4 & 64.0 \\
\hline \multirow[t]{2}{*}{ TIMP3 } & benign & 146 & 39.0 & 8.2 & 65 & 35.4 & 4.6 & 48 & 41.7 & 12.5 \\
\hline & malignant & 254 & 46.5 & 15.8 & 113 & 47.8 & 19.5 & 85 & 37.8 & 14.1 \\
\hline
\end{tabular}

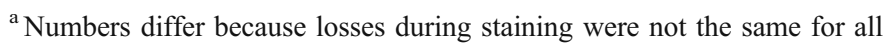

${ }^{\mathrm{b}}$ Staining is reported as \%. Because the proportion of stained specimens was very small, stromal staining was dichotomized into no vs. any stain; epithelial staining was classified as no, weak, or strong

related to staining ( $p=0.03$ for benign and $p=0.01$ for malignant); ever users were less likely to have any staining than never users.

There was no statistically significant association of MMP1, MMP12, and TIMP3 with breast density in the entire study population (Fig. 2). After stratification by ethnicity, we noted several discrepant associations. In Japanese women, density was inversely associated with MMP1 expression $(31.5 \%$ for any stain vs. $41.3 \%$ for no stain in malignant stromal tissue; $p=0.04)$. The same trend, though not significant, was observed in epithelium. In contrast, percent density was higher in Caucasian women with more extensive MMP1 expression; the respective values for malignant stromal tissue were $40.7 \%$ vs. $32.1 \%$ $(p=0.12)$.

Although not statistically significant, mean percent density was lower with more extensive TIMP3 expression both in stromal and in epithelial tissue (Fig. 2). In stromal tissue, mean density was 40.0 vs. $36.9(p=0.28)$ for no vs. any stain in benign tissue; the respective values for malignant tissue were 36.0 vs. $35.7(p=0.73)$. In benign epithelial tissue, mean density was $43.9 \%$ vs. $31.5 \%$ for no vs. strong stain $(p=0.10)$; the respective values for malignant epithelial tissue were $39.2 \%$ vs. $31.9 \%$ $(p=0.18)$. With one exception (malignant stromal tissue of Caucasians), the inverse association was consistent across ethnic groups.

\section{Discussion}

This exploratory study detected no significant associations between mammographic density and expression of MMP1, MMP12, and TIMP3 in breast tissue. However, we found TIMP3 to be less expressed in tissue from breast cancer cases with high than low breast density. Despite its lack of statistical significance, the consistency of this trend across ethnic groups and tissue types suggests an inverse associ- 

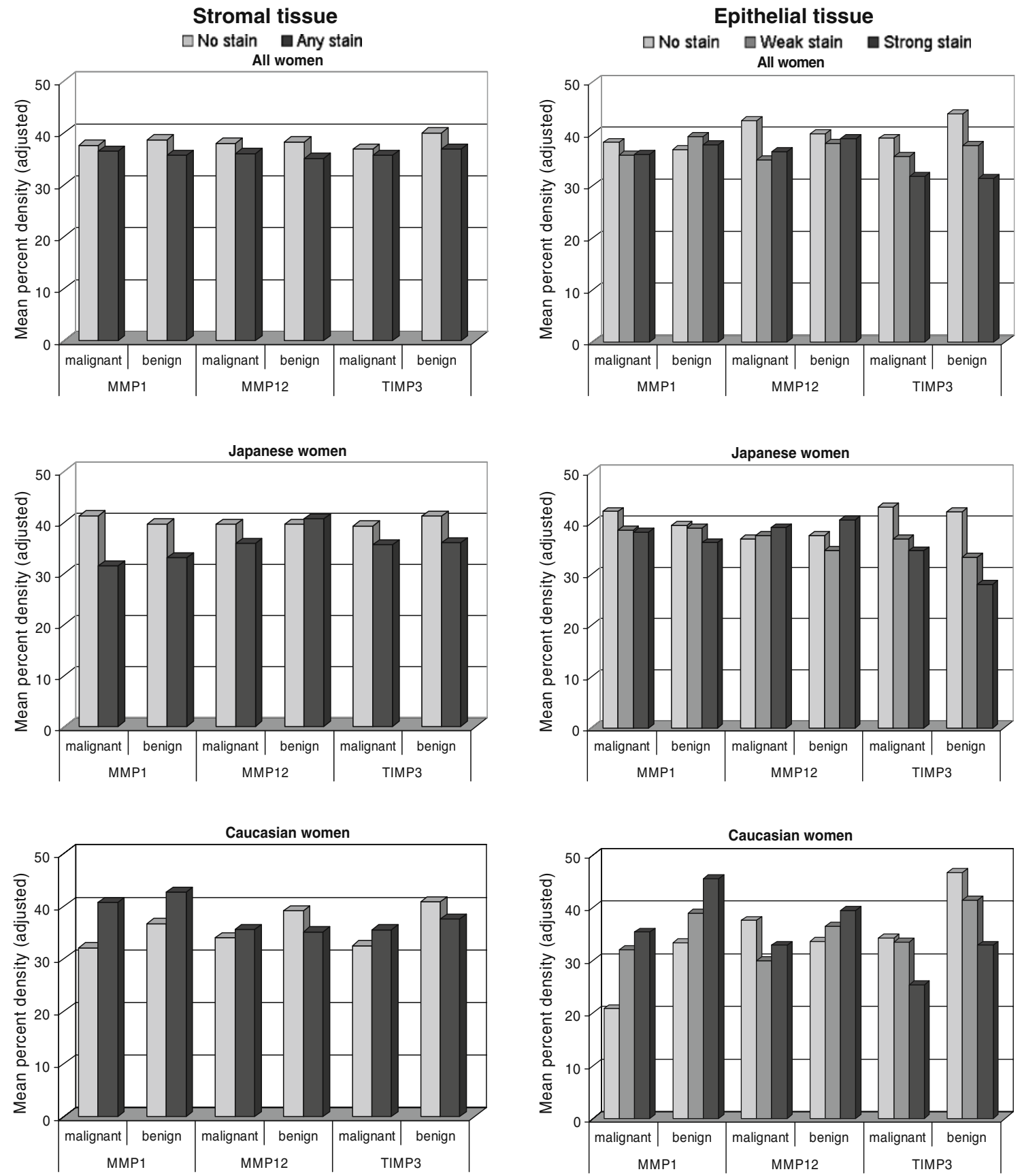

${ }^{*}$ Adjusted for age at mammogram, BMI, ethnicity, parity, age at first live birth, age at menarche, menopausal status, hormone use at mammogram, family history of breast cancer, and tumor stage.

Fig. 2 Percent density for MMP1, MMP12, and TIMP3 by tissue type and ethnicity (Adjusted for age at mammogram, BMI, ethnicity, parity, age at first live birth, age at menarche, menopausal status, hormone use at mammogram, family history of breast cancer, and tumor stage)

ation that needs to be confirmed in future studies with additional proteins. Whereas the expression of markers differed little by ethnicity, MMP1 expression was associated with higher breast density among Caucasian women but inversely related to breast density in Japanese women. The results were analogous in epithelial and stromal tissue as well as malignant and benign samples (Fig. 2). This observation may be due to chance or it may indicate genetic or acquired differences in breast tissue.

Although not entirely consistent, hyperplasia, atypical hyperplasia, and carcinoma in situ appear to be associated with higher percent densities in some studies $[6,7,22]$. 
Associations of high density with intra- and extralobular fibrosis [23] as well as higher collagen density [3] have also been described. To our knowledge, no other studies examined MMPs and their effect on breast density as of this date. Contrary to our findings, a study with a very small sample size found high breast density to be associated to an increased amount of TIMP3 in tissues surrounding benign lesions [12]. The authors hypothesized that TIMP3 may influence matrix deposition leading to higher breast density or that TIMP3 may act through alteration of insulinlike growth factors that influence cell proliferation. A possible explanation for the discrepancy of the two studies is that the balance between MMPs and TIMPs is more important than just the expression of one protein, but the expression of other MMPs and TIMPs, in particular MMP2, MMP9, TIMP1, TIMP2, and their ratios, would be needed to assess the overall balance.

MMPs are thought to be secreted not only by tumor cells, but mainly by the surrounding reactive microenvironment. Host stromal cells such as fibroblasts, endothelial and also infiltrating inflammatory cells respond to nearby tumor cells by induction of MMPs [24, 25]. These degrade the basement membrane and ECM components to a more "watery" consistence, which is radiographically denser than fat; this facilitates tumor invasion and formation of metastases $[8,26]$. Thus, MMPs also contribute to early steps of tumor progression, including tumor promotion and angiogenesis $[9,10]$. As a result of the activity of MMPs, cell-cell and cell-ECM interactions are altered, new biologically active ECM molecules are generated, and the bioavailability and activity of many growth factors and cytokines is modified. We indeed found stronger expression of all MMPs in malignant than benign tissue. The MMP1 findings in Caucasian women agree with the hypothesis that MMPs might contribute to the associated higher breast cancer risk. However, the opposing findings in Japanese women are difficult to explain and may be due to the multiple comparisons since there is little difference in risk factors by ethnicity (Table 1). To evaluate the role of MMP1 in more depth, concise staining panels including TIMP1 are needed.

A disruption in the balance between the MMPs and their natural inhibitors, TIMPs has been implicated in the progression of cancer [11]. Overexpression of TIMPs appears to inhibit primary tumor growth in mice [27, 28] as well as reduce tumor invasion and metastasis [11, 29, 30]. In the present study, TIMP3 expression was lower in stromal cells of malignant than benign tissue; however, this was not the case for epithelial cell expression. One possible hypothesis would be that the lower TIMP3 expression in women with high breast density may affect the activity of growth factors and influence matrix deposition that translates into altered breast density. If low TIMP expression leads to greater MMP activity, which in turn may lead to higher breast density and a greater carcinogenic potential of breast cells, it may be partially responsible for the increased breast cancer risk associated with breast density. However, TIMP3 has other bio-cellular functions, not related to MMP inhibition, such as induction of apoptosis [11, 31] or inhibition of endothelial cell motility and proliferation [32]. These might also be possible mechanisms leading to low breast density and its associated breast cancer risk.

As a result of the pilot nature of this project, the low power seriously limited our ability to draw definite conclusions. Our choice of markers was based on a literature review regarding relevant MMPs in breast tissue and breast cancer, availability of antibodies, and experience at our institution. MMP1, MMP3, MMP9, and MMP12 were shown to be involved in mammary carcinogenesis $[33,34]$. TIMP3 was selected because a previous report had detected an association with breast density [12]. However, the markers in this study represent only part of the proteins that are needed for a complete evaluation of MMP and TIMP activity. Therefore, one major limitation of our study is the incompleteness of MMP panels. In particular, the low staining results of MMP9 and MMP3 might be due to high levels of TIMP1, their natural inhibitor, which needs to be assessed in future studies for a thorough understanding of their interactions. Bias due to intratumor heterogeneity may have been introduced when sections for the construction of TMAs were selected because we did not distinguish between specific areas of the tumor, i.e., center versus periphery or depth of invasion. The limited response rate, unavailability of tissue, and the loss of tissue cores may have led to selection bias. We also acknowledge that the so-called benign breast tissue was obtained from tumor blocks of women diagnosed with breast cancer. Therefore, these samples may not be equivalent to breast tissue from women with no clinical or mammographic abnormalities. To minimize the risk of misclassification, we reassessed the histopathology in individual sections on the TMAs after staining as to ensure that malignancy status had been assigned correctly.

On the other hand, this study had several strengths. Our population included pathologic specimens for ethnically diverse breast cancer cases from a population-based tissue repository, a relatively new research approach [19]. The availability of many demographic and reproductive variables in a study of tissue characteristics provided us with the opportunity for statistical adjustments. Furthermore, we obtained mammograms before the participants were diagnosed with breast cancer, which gives us the opportunity to assess density on mammograms without confounding by tumor masses. This study benefited from the use of a high throughput TMA approach which enabled us to stain large numbers of samples under comparative conditions without depletion of the tissue block for further research. The 
investigation adds to the limited literature of using TMAs in epidemiologic studies and to the variety of markers measured in TMAs $[35,36]$. To our knowledge, no previous studies have examined the association of mammographic density with MMPs. This novel approach showed trends which might suggest a possible association of breast density with TIMPs, which might be a step towards revealing the histopathologic mechanism underlying breast density. However, to fully understand the role of MMPs and their inhibitors, it is of utmost interest to study complete panels of MMPs and their inhibitors, in particular MMP2, MT1-MMP, TIMP1, and TIMP2. Future investigations into activities and ratios of these proteases as well as other pathways such as inflammation [37], may lead to identification of patients at high risk for developing breast cancer or aggressive tumors [37] and could lead to innovative breast cancer prevention strategies [26].

Acknowledgments The breast pathology study and the case-control study were funded by grants from the National Cancer Institute (R21 CA1080250 and R01 CA85265; PI: GM). The Multiethnic Cohort Study has been supported by USPHS (National Cancer Institute) Grant R37 CA54281 (PI: Dr. L.N. Kolonel) and the Hawaii Tumor Registry was funded by NCI contract N01PC35137-18-0-1. We are grateful to the study participants and to the staff of the Hawaii Tumor Registry for their support. We thank Hugh Luk for the preparation of the TMAs, Hermina Borgerink and Suzanne Cashin for the staining of the TMAs, and Joseph Finley for the assessment of stains

Open Access This article is distributed under the terms of the Creative Commons Attribution Noncommercial License which permits any noncommercial use, distribution, and reproduction in any medium, provided the original author(s) and source are credited.

\section{References}

1. McCormack VA, dos Santos Silva I (2006) Breast density and parenchymal patterns as markers of breast cancer risk: a metaanalysis. Cancer Epidemiol Biomarkers Prev 15:1159-1169

2. Thurfjell E (2002) Breast density and the risk of breast cancer. N Engl J Med 347:866

3. Alowami S, Troup S, Al-Haddad S et al (2003) Mammographic density is related to stroma and stromal proteoglycan expression. Breast Cancer Res 5:R129-R135

4. Boyd NF, Rommens JM, Vogt K et al (2005) Mammographic breast density as an intermediate phenotype for breast cancer. Lancet Oncol 6:798-808

5. Warren R, Lakhani SR (2003) Can the stroma provide the clue to the cellular basis for mammographic density? Breast Cancer Res 5:225-227

6. Bartow SA, Pathak DR, Mettler FA (1990) Radiographic microcalcification and parenchymal pattern as indicators of histologic "high-risk" benign breast disease. Cancer 66:1721-1725

7. Urbanski S, Jensen HM, Cooke G et al (1988) The association of histological and radiological indicators of breast cancer risk. Br J Cancer 58:474-479

8. Ghajar CM, Bissell MJ (2008) Extracellular matrix control of mammary gland morphogenesis and tumorigenesis: insights from imaging. Histochem Cell Biol 130:1105-1118
9. Koshiba T, Hosotani R, Wada M et al (1998) Involvement of matrix metalloproteinase-2 activity in invasion and metastasis of pancreatic carcinoma. Cancer 82:642-650

10. Coussens LM, Tinkle CL, Hanahan D et al (2000) MMP-9 supplied by bone marrow-derived cells contributes to skin carcinogenesis. Cell 103:481-490

11. Baker AH, George SJ, Zaltsman AB et al (1999) Inhibition of invasion and induction of apoptotic cell death of cancer cell lines by overexpression of TIMP-3. Br J Cancer 79:1347-1355

12. Guo YP, Martin LJ, Hanna W et al (2001) Growth factors and stromal matrix proteins associated with mammographic densities. Cancer Epidemiol Biomarkers Prev 10:243-248

13. Maskarinec G, Pagano I, Lurie G et al (2005) Mammographic density and breast cancer risk: the multiethnic cohort. Am J Epidemiol 162:743-752

14. Kolonel LN, Henderson BE, Hankin JH et al (2000) A multiethnic cohort in Hawaii and Los Angeles: baseline characteristics. Am J Epidemiol 151:346-357

15. Verheus M, Maskarinec G, Erber E et al (2009) Mammographic density and epithelial histopathologic markers. BMC Cancer 9:182

16. Maskarinec G, Erber E, Verheus M et al (2009) Soy consumption and histopathologic markers in breast tissue using tissue microarrays. Nutr Cancer 61(5):708-716

17. Byng JW, Boyd NF, Fishell E et al (1994) The quantitative analysis of mammographic densities. Phys Med Biol 39:16291638

18. Stone J, Gunasekara A, Martin LJ et al (2003) The detection of change in mammographic density. Cancer Epidemiol Biomarkers Prev 12:625-630

19. Goodman MT, Hernandez BY, Hewitt S et al (2005) Tissues from population-based cancer registries: a novel approach to increasing research potential. Hum Pathol 36:812-820

20. Anderson WF, Luo S, Chatterjee $\mathrm{N}$ et al (2008) Human epidermal growth factor receptor- 2 and estrogen receptor expression, a demonstration project using the residual tissue respository of the Surveillance, Epidemiology, and End Results (SEER) program. Breast Cancer Res Treat 113(1):189-196

21. Shi SR, Key ME, Kalra KL (1991) Antigen retrieval in formalinfixed, paraffin-embedded tissues: an enhancement method for immunohistochemical staining based on microwave oven heating of tissue sections. J Histochem Cytochem 39:741-748

22. Wellings SR, Wolfe JN (1978) Correlative studies of the histological and radiographic appearance of the breast parenchyma. Radiology 129:299-306

23. Bright RA, Morrison AS, Brisson J et al (1988) Relationship between mammographic and histologic features of breast tissue in women with benign biopsies. Cancer 61:266-271

24. Coussens LM, Werb Z (1996) Matrix metalloproteinases and the development of cancer. Chem Biol 3:895-904

25. Nelson AR, Fingleton B, Rothenberg ML et al (2000) Matrix metalloproteinases: biologic activity and clinical implications. J Clin Oncol 18:1135-1149

26. Egeblad M, Werb Z (2002) New functions for the matrix metalloproteinases in cancer progression. Nat Rev Cancer 2:161-174

27. Wang M, Liu YE, Greene J et al (1997) Inhibition of tumor growth and metastasis of human breast cancer cells transfected with tissue inhibitor of metalloproteinase 4. Oncogene 14:27672774

28. Khokha R, Denhardt DT (1989) Matrix metalloproteinases and tissue inhibitor of metalloproteinases: a review of their role in tumorigenesis and tissue invasion. Invasion Metastasis 9:391405

29. Albini A, Melchiori A, Santi L et al (1991) Tumor cell invasion inhibited by TIMP-2. J Natl Cancer Inst 83:775-779 
30. Valente P, Fassina G, Melchiori A et al (1998) TIMP-2 overexpression reduces invasion and angiogenesis and protects B16F10 melanoma cells from apoptosis. Int J Cancer 75:246253

31. Ahonen M, Baker AH, Kahari VM (1998) Adenovirus-mediated gene delivery of tissue inhibitor of metalloproteinases-3 inhibits invasion and induces apoptosis in melanoma cells. Cancer Res 58:2310-2315

32. Anand-Apte B, Bao L, Smith R et al (1996) A review of tissue inhibitor of metalloproteinases-3 (TIMP-3) and experimental analysis of its effect on primary tumor growth. Biochem Cell Biol 74:853-862

33. Sternlicht MD, Bissell MJ, Werb Z (2000) The matrix metalloproteinase stromelysin-1 acts as a natural mammary tumor promoter. Oncogene 19:1102-1113
34. Balduyck M, Zerimech F, Gouyer Vet al (2000) Specific expression of matrix metalloproteinases 1, 3, 9 and 13 associated with invasiveness of breast cancer cells in vitro. Clin Exp Metastasis 18:171-178

35. Hernandez BY, Frierson HF, Moskaluk CA et al (2005) CK20 and CK7 protein expression in colorectal cancer: demonstration of the utility of a population-based tissue microarray. Hum Pathol $36: 275-281$

36. Yang XR, Charette LA, Garcia-Closas M et al (2006) Construction and validation of tissue microarrays of ductal carcinoma in situ and terminal duct lobular units associated with invasive breast carcinoma. Diagn Mol Pathol 15:157-161

37. Hojilla CV, Wood GA, Khokha R (2008) Inflammation and breast cancer: metalloproteinases as common effectors of inflammation and extracellular matrix breakdown in breast cancer. Breast Cancer Res 10:205 